\title{
Host-derived RANKL is responsible for osteolysis in a C4-2 human prostate cancer xenograft model of experimental bone metastases Colm Morrissey ${ }^{1}$, Paul L Kostenuik ${ }^{3}$, Lisha G Brown ${ }^{1}$, Robert L Vessella ${ }^{1,2}$ and Eva Corey*1
}

\author{
Address: ${ }^{1}$ Department of Urology, University of Washington, Seattle, WA, USA, ${ }^{2}$ Puget Sound VA Medical Center, Seattle, WA, USA and ${ }^{3}$ Amgen \\ Inc, Thousand Oaks, CA, USA \\ Email: Colm Morrissey - cmorriss@u.washington.edu; Paul L Kostenuik - paulk@amgen.com; Lisha G Brown - brown@u.washington.edu; \\ Robert L Vessella - vessella@u.washington.edu; Eva Corey* - ecorey@u.washington.edu \\ * Corresponding author
}

Published: 3 August 2007

BMC Cancer 2007, 7:148 doi:10.1 186/147|-2407-7-148
Received: 3 April 2007

Accepted: 3 August 2007

This article is available from: http://www.biomedcentral.com/I47/-2407/7//48

(C) 2007 Morrissey et al; licensee BioMed Central Ltd.

This is an Open Access article distributed under the terms of the Creative Commons Attribution License (http://creativecommons.org/licenses/by/2.0), which permits unrestricted use, distribution, and reproduction in any medium, provided the original work is properly cited.

\begin{abstract}
Background: C4-2 prostate cancer (CaP) cells grown in mouse tibiae cause a mixed osteoblastic/ osteolytic response with increases in osteoclast numbers and bone resorption. Administration of osteoprotegerin (OPG) blocks these increases, indicating the critical role of RANKL in osteolysis in this model. The objective of our study was to investigate whether RANKL expressed by tumor cells (human origin) directly stimulates osteolysis associated with the growth of these cells in bone or whether the increased osteolysis is caused by RANKL expressed by the host environment cells (murine origin). The relative contribution of tumor-vs. host-derived RANKL has been difficult to establish, even with human xenografts, because murine and human RANKL are both capable of stimulating osteolysis in mice, and the RANKL inhibitors used to date (OPG and RANK-Fc) inhibit human and murine RANKL.

Methods: To address this question we used a neutralizing, antibody (huRANKL MAb), which specifically neutralizes the biological activities of human RANKL and thereby the contribution of C4-2 derived RANKL in this tibial injection model of experimental bone metastases.

Results: Administration of huRANKL MAb did not inhibit the osteolytic response of the bone to these cells, or affect the establishment and growth of the C4-2 tumors in this environment.

Conclusion: In conclusion, our results suggest that in this model, murine RANKL and not the tumor-derived human RANKL is the mediator of the osteolytic reaction associated with C4-2 growth in bone. We hypothesize that C4-2 cells express other factor/s inducing host production of RANKL, thereby driving tumor-associated osteolysis.
\end{abstract}

\section{Background}

Prostate cancer $(\mathrm{CaP})$ predominantly metastasizes to the bone, and bone metastases are the main cause of morbidity. While CaP metastases are usually osteoblastic in nature [1-3], there is an osteolytic component to the dis- ease $[4,5]$ which is manifested by increases in osteolytic markers in the serum and urine of patients with advanced $\mathrm{CaP}$ [6-8]. Increased bone resorption is also a prognostic factor for skeletal-related events in metastatic CaP [9]. 
However, how CaP cells induce an increased osteolytic reaction is not fully understood.

The RANKL/RANK/OPG system is critical in regulating osteoclastogenesis, and therefore is involved in bone remodeling (reviewed in [10]). Osteoclastogenesis is regulated by the interaction between receptor activator of NFKB ligand (RANKL) and its receptor RANK. RANK is expressed on bone marrow-derived osteoclast progenitors, and its activation upon binding of RANKL is required for differentiation of these progenitors into osteoclasts $[10,11]$. Osteoprotegerin (OPG), a soluble decoy receptor for RANKL inhibits osteoclastogenesis by interfering with RANKL-RANK interactions [12]. Recently, RANKL has been identified as a potential mediator of cancer-induced bone destruction in humans [13].

Our interest in the role of RANKL/RANK/OPG signaling in deregulation of bone remodeling-associated $\mathrm{CaP}$ bone metastases originally led us to examine whether $\mathrm{CaP}$ cells in the bone environment expressed these factors. We have shown that normal prostate and primary $\mathrm{CaP}$ express RANKL and OPG, and the levels of RANKL and OPG are increased in CaP bone metastases vs. those in primary tumors and soft-tissue metastases [14]. CaP cell lines also express RANK and RANKL [14-16], and RANKL was reported to be instrumental in induction of osteoclastogenesis by $\mathrm{CaP}$ cells in vitro [16]. Soluble RANKL released from CaP cells by MMP-7 was shown to play a role in establishment of CaP bone metastases and osteolysis associated with CaP bone lesions [17]. These data constitute additional evidence of a role for RANK/RANKL signaling in $\mathrm{CaP}$ bone metastases.

Results of preclinical studies have shown that inhibition of RANK/RANKL signaling decreases tumor growth and/ or establishment and prevented osteolysis in $\mathrm{CaP}[16,18$ 22] and other tumor types [23-25] in the bone environment. While these data are promising with regard to treatment of advanced CaP, acquiring additional understanding of the mechanisms of induction of osteoclastogenesis associated with prostate tumors in the bone is a critical step to enable further advances in this area. Cancer cells may cause osteolysis directly by expression of RANKL or indirectly by inducing host production of RANKL. The relative contribution of tumor-versus hostderived RANKL has been difficult to establish, even with human xenograft models, because murine and human RANKL both cause osteolysis in mice. Furthermore, the RANKL inhibitors used to date (OPG and RANK-Fc) $[16,18,20,22]$ or soluble RANK [19] inhibit both human and murine RANKL.

The purpose of this study was to determine whether RANKL expressed by C4-2 CaP cells is directly involved in stimulation of osteoclastogenesis associated with the growth of these cells in the bone environment. We have used a model of experimental CaP bone metastases consisting of direct injection of human C4-2 cells into mouse tibiae and huRANKL MAb, an anti-human RANKL neutralizing antibody to address this question. The use of huRANKL MAb, has enabled us to separate the effect of bone (murine) and tumor (human) RANKL. Our results indicate that the human RANKL expressed by C4-2 cells exerted little or no effect in this system and that RANKL expressed by the host cells within the bone environment is responsible for the stimulation of osteolysis. This implies that CaP cells express factor/s other than RANKL in this murine bone xenograft model that (a) stimulates host cells to produce RANKL and/or (b) directly stimulates osteoclastogenesis.

\section{Methods}

\section{Tissue culture}

C4-2 prostate cancer cells, a subline of LNCaP cells, were purchased from Urocor, Inc. (Oklahoma City, OK) and maintained under standard tissue culture conditions in RPMI 1640 (Invitrogen Corp. Carlsbad, CA) supplemented with $10 \%$ fetal bovine serum (FBS) (Atlanta Biologicals, Atlanta, GA).

\section{Effects of OPG-Fc and huRANKL MAb on huRANKL- induced $\mathrm{Ca}^{2+}$ release in mice}

All animal procedures were performed in compliance with the University of Washington and Amgen Institutional Animal Care and Use Committees and NIH guidelines. Initially to characterize the specificity of the huRANKL MAb to bind to human RANKL young male BDF1 mice ( $4-5$ weeks old, $\mathrm{n}=5$ per group) were injected subcutaneously with 1,3 , or $10 \mathrm{mg} / \mathrm{kg}$ huRANKL MAb (AMG 161, Amgen, Inc., Thousand Oaks, CA), 3 mg/kg OPG-Fc (Amgen, Inc.), or PBS. Animals were then challenged twice daily (by subcutaneous injection morning and evening) with either human RANKL $(0.5 \mathrm{mg} / \mathrm{kg}$, Amgen, Inc.) or PBS for 6 days. Blood was collected 3 hours after each morning challenge. Blood $\mathrm{Ca}^{2+}$ was measured using a $\mathrm{Ca}^{2+} / \mathrm{pH}$ analyzer (Model 634 , Chiron Diagnostics, Halstead, UK).

\section{Effects of OPG-Fc and huRANKL MAb on systemic TRACP- $5 b$ levels in mice}

12-week-old female BALB/c mice ( $\mathrm{n}=5$ per group) were injected with a single subcutaneous injection of PBS, OPG-Fc $(10 \mathrm{mg} / \mathrm{kg})$, or huRANKL MAb $(10 \mathrm{mg} / \mathrm{kg})$. TRACP-5b activity in serum samples collected one hour before (baseline) and $72 \mathrm{~h}$ after the treatment was measured using the mouse TRAP ${ }^{\mathrm{TM}}$ Assay (SBA Sciences, Turku, Finland). 


\section{Effect of huRANKL MAb on experimental CaP bone metastases}

Once the neutralizing activity and specificity of the huRANKL MAb in vivo were determined, we set up to investigate the effects of inhibition of human RANKL on osteolysis associated with $\mathrm{C} 4-2$ growth in the murine bone. These experiments require use of SCID male mice. We are unaware of any data indicating that bone remodeling would be different between wild-type and SCID mice. Four-to six-week-old male SCID mice were injected with approximately $1 \times 10^{5} \mathrm{C} 4-2$ cells in $10 \mu \mathrm{L}$ into the tibiae as described previously [26,27]. Three groups of 10 animals each were used: 1) a control group, subcutaneous injection of PBS twice a week; 2) a prevention group, subcutaneous injection of huRANKL MAb (5 mg/kg) twice a week, starting at time of tumor-cell injection; and 3) a treatment group, subcutaneous injection of PBS twice a week until week 3, and then injections of huRANKL MAb ( $5 \mathrm{mg} / \mathrm{kg}$ ) twice a week until sacrifice. Blood samples were drawn from animals weekly for determination of serum prostate specific antigen (PSA) levels starting at week 3 after tumor-cell injection, to monitor tumor growth (IMx Total PSA assay, Abbott Laboratories, Abbott Park, IL). All animals were sacrificed 8 weeks after tumor-cell injection. Prior to sacrifice, all mice were radiographed with a Model MX-20 Laboratory radiography System (Faxitron X-Ray Corp., Wheeling, IL). Bone mineral density (BMD) was measured using a PIXImus Lunar densitometer (GE Healthcare, Waukesha, WI). Tibiae with tumors from 5 animals per group were demineralized and embedded in paraffin. The remaining 5 tibiae with tumors from each group were embedded in methacrylate $[26,28]$ for bone histomorphometrical (BHM) analysis. At sacrifice, serum was collected for determination of mouse TRACP-5b activity, using the Mouse TRAP ${ }^{\mathrm{TM}}$ Assay, and serum $\mathrm{Ca}^{2+}$ levels, using a PHM $240 \mathrm{pH} /$ ion meter with an ISE25Ca $\mathrm{Ca}^{2+}$ electrode (Radiometer analytical, Lyon, France).

\section{Bone histomorphometry}

Six-micrometer longitudinal sections of undecalcified tibiae embedded in methacrylate and stained with Goldner's stain were used. BHM analysis was performed in the middle of the tibia, in the area $0.525-1.225 \mathrm{~mm}$ below the growth plate ( $\mathrm{n}=5$ per group, Skeletech, Inc., Bothell, WA). The percentage of bone volume in tissue volume $(\% \mathrm{BV} / \mathrm{TV})$, tumor volume in tissue volume $(\% \mathrm{TuV} / \mathrm{TV})$, trabecular thickness in $\mu \mathrm{m}$ (Tb.Th.), trabecular number per mm (Tb.N.), trabecular separation in $\mu \mathrm{m}$ (Tb.Sp.), the ratio of osteoblast perimeter to bone perimeter as a ratio (Ob.Pm./B.Pm.), and the ratio of osteoclast number to bone surface (N.Oc./BS) were determined. The \%BV/TV and $\mathrm{TuV} / \mathrm{TV}$ was also measured in the whole longitudinal section.

\section{Immunohistochemistry}

Antigen retrieval was performed on $5 \mu \mathrm{m}$ paraffin sections of tumored tibiae in $10 \mathrm{mM}$ citrate buffer ( $\mathrm{pH} \mathrm{6)}$ for 20 $\min$ at $120^{\circ} \mathrm{C}$ in an autoclave. The slides were then incubated with $3 \% \mathrm{H}_{2} \mathrm{O}_{2}$ for $10 \mathrm{~min}$ to block endogenous peroxidase activity, with avidin/biotin blocking solution (Vector Laboratories Inc. Burlingame, CA) for $30 \mathrm{~min}$, and finally with a 5\% chicken/goat/horse serum solution for 1 $\mathrm{h}$ at room temperature. The tissue was stained with a rabbit polyclonal anti-human RANKL antibody (AB1862, 1/ 1000 dilution, Chemicon International, Temecula, CA) for $1 \mathrm{~h}$ at room temperature. Control slides were incubated with rabbit IgG under the same conditions as the primary antibody. All slides were then incubated with a biotinylated goat anti-rabbit secondary antibody (1:150, Vector Laboratories Inc.) for $30 \mathrm{~min}$ at room temperature, and immunoreactivity was detected using the Vectastain $\mathrm{ABC}$ kit (Vector Laboratories Inc.) and stable DAB (Invitrogen Corp.).

\section{Data analyses}

Statistical analyses of the results were performed using Prism software (Prism Graphpad, San Diego, CA). Significance of differences was evaluated using paired and unpaired Student's t tests as appropriate, with $p$ values $\leq$ 0.05 indicating statistical significance.

\section{Results \\ Determination of the specificity of huRANKL MAb}

Effects of huRANKL MAb on human RANKL-induced $\mathrm{Ca}^{2+}$ release in mice

In our first experiments, we used normal non-tumor-bearing wild-type mice to establish that the anti-huRANKL MAb effectively inhibits human RANKL-induced increases in serum ionized $\mathrm{Ca}^{2+}$ levels in vivo, without showing evidence for the inhibition of murine RANKL. Administration of human RANKL to mice increased serum $\mathrm{Ca}^{2+}$ levels. huRANKL MAb inhibited these effects in a concentration-dependent manner. Administration of high doses of huRANKL MAb $(10 \mathrm{mg} / \mathrm{kg})$ completely inhibited $\mathrm{Ca}^{2+}$ release stimulated by human RANKL, returning $\mathrm{Ca}^{2+} \mathrm{lev}-$ els to control levels. OPG-Fc used as a positive control for inhibition of RANKL-induced osteolysis also inhibited $\mathrm{Ca}^{2+}$ release, reducing $\mathrm{Ca}^{2+}$ levels beyond control levels (Figure 1A).

\section{Effects of OPG-Fc and huRANKL MAb on systemic TRACP-5b activity} in mice

The administration of OPG-Fc to mice significantly decreased systemic TRACP-5b activity in serum of treated mice $(p<0.0001)$. However, huRANKL MAb treatment was unable to inhibit TRACP-5b activity in the serum of mice $(p=0.1769)$ (Figure $1 \mathrm{~B})$. After obtaining data that huRANKL MAb inhibits human RANKL, but not mouse RANKL activity in vivo, we set out to examine the effects of 
A

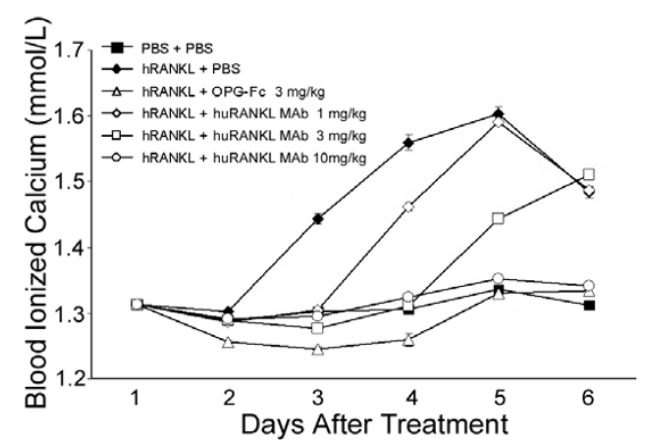

B

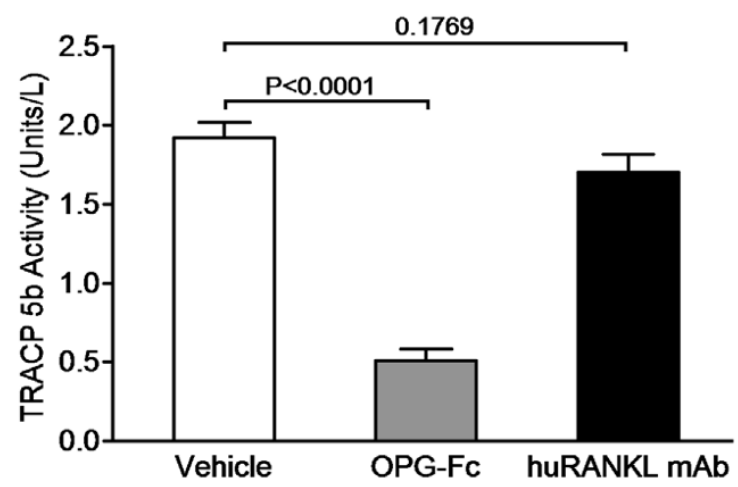

Figure I

A: Measurement of serum calcium levels in OPG-Fc- and huRANKL MAb-treated mice challenged with human RANKL. Young male BDFI mice (4-5 weeks old) were challenged twice daily (by SC injection, morning and evening) with either PBS (closed squares) or with human RANKL $(0.5$ $\mathrm{mg} / \mathrm{kg}$, closed diamonds) for 6 days. Immediately prior to the first human RANKL challenge, mice were given a single SC injection of either PBS or OPG-Fc ( $3 \mathrm{mg} / \mathrm{kg}$; open triangle), or huRANKL MAb $(\mathrm{I}, 3$, or $10 \mathrm{mg} / \mathrm{kg})$. Results are expressed as mean \pm SE. B: Systemic levels of TRACP-5b in sera of mice challenged with OPG-Fc and huRANKL MAb. 12-week-old female BALB/c mice ( $n=5$ per group) were given a single subcutaneous injection of PBS, (Vehicle), OPG-Fc (10 mg/kg), or huRANKL MAb ( $10 \mathrm{mg} / \mathrm{kg})$. TRACP-5b concentration was detected in sera one hour before (baseline) and $72 \mathrm{~h}$ after treatment (Mouse TRAP Assay, SBA Sciences). TRACP-5b concentration was significantly different between Vehicle and OPG-Fc treated animals $(p<0.000$ I). TRACP-5b concentration was not significantly different between Vehicle and huRANKL MAb treated animals $(p=0.1769)$. Results are expressed as mean \pm SE.

huRANKL MAb on osteolysis associated with the growth of C4-2 in the bone environment.

\section{Effects of huRANKL MAb on experimental CaP bone metastases}

Once we had established the anti-human RANKL specificity of the huRANKL MAb, we used the C4-2 tibial injection model of experimental bone metastases in SCID mice in combination with the huRANKL MAb to test our hypothesis. All animals had tumor cells growing in the tibiae, as demonstrated by serum PSA levels that were detectable at week 2 after tumor-cell injection and increased thereafter. Expression of RANKL in C4-2 tumors in tibiae was confirmed by immunohistochemistry (Figure 2A). Administration of huRANKL MAb did not significantly alter establishment or growth of tumors in the bone as represented by serum levels of PSA (Figure 2B) and the final tumor volume (Table 1).

Radiography of the tibiae was used to assess the impact of the C4-2 tumors on the integrity of the bone (Figure 3A). In the site of injection adjacent to the growth plate, the cortical shaft was eroded and C4-2 tumor cells had replaced the marrow and both the trabecular bone and cortical shaft had been degraded in all groups. In some cases tumor was present outside the cortical shaft (Figure $3 \mathrm{~A})$; no significant differences in bone destruction were observed between animals from either groups (Table 1). The destruction of bone associated with the growth of C42 cells in the tibiae was demonstrated by decreases in BMD, similarly to our previous data $[18,27]$; however, administration of huRANKL MAb did not have any significant effects on BMD of tumored or contralateral tibiae (Figure 3B).

Histomorphometrical analyses showed that huRANKL MAb did not alter bone volume (control $v s$. prevention: $p$ $=0.5146$; control $v s$. treatment: $p=0.6467$ ) or tumor volume (control vs. prevention: $p=0.5920$; control $v s$. treatment: $p=0.5232$ ) both measured in the region next to the growth plate. Other measurements included trabecular thickness (control $v s$. prevention: $p=0.6182$; control $v s$. treatment: $p=0.6140$ ), trabecular number (control $v s$. prevention: $p=0.9855$; control $v s$. treatment: $p=0.7119$ ) or trabecular separation (control vs. prevention: $p=$ 0.8950 ; control $v s$. treatment: $p=0.9188$ ). A significant increase in the ratio of osteoblast perimeter to bone perimeter between control $v$ s. prevention $(p=0.0227)$ and osteoclast number to bone surface between control $v$ s. treatment ( $p=0.0238$ ) was detected (Table 1$)$. Since the differences in the ratio of osteoclast number to bone surface were detected only between the control and treatment groups, but not control $v s$ prevention groups, we speculate that these differences might be associated with the anarchic nature of the bone response to the C4-2 cells and may not be biologically relevant. 
A

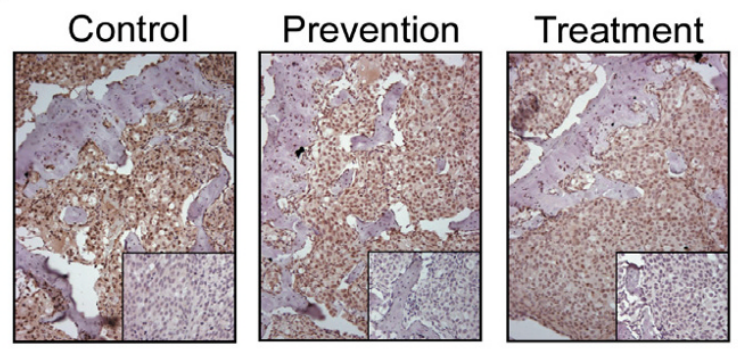

B

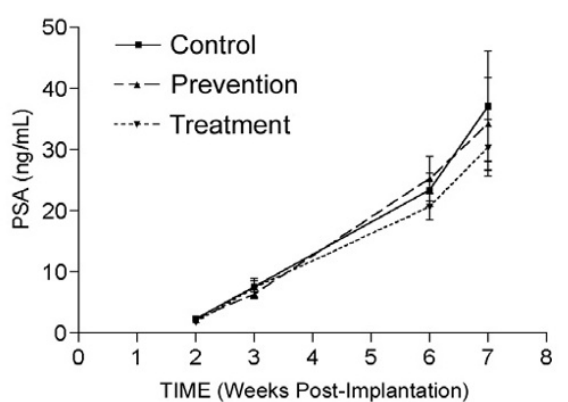

Figure 2

A: Immunohistochemical analysis of RANKL in C4-2 tumored tibiae of control, prevention, and treatment groups. Paraffin-embedded C4-2 tumored tibiae of the SCID mice were sectioned and stained for RANKL (negative control staining is shown in inset box). The tumor cells stained positively for RANKL. B: Blood was collected to determine serum PSA levels by IMx Total PSA assay. Serum PSA levels were not significantly different between the C42 control with PBS injections (control), C4-2 with a concomitant subcutaneous injection of huRANKL MAb $(5 \mathrm{mg} / \mathrm{kg}$ once a week) at implantation (prevention group), or C4-2 with a subcutaneous injection of huRANKL MAb (5 mg/kg biweekly, starting 3 weeks after implantation of C4-2 cells) (treatment group). Results are presented as mean $\pm \mathrm{SE}$.

To further evaluate the effects of huRANKL MAb on C4-2induced osteolysis we measured levels of mouse serum TRACP-5b enzymatic activity. No significant differences in TRACP-5b activity were detected between the groups (Figure 4A). In contrast there were significant differences in serum $\mathrm{Ca}^{2+}$ concentrations between control and prevention $(p=0.012)$, and prevention and treatment $(p=$ $0.0225)$, while no differences were detected between control and treatment groups (Figure 4B).

\section{Discussion}

Even in patients with osteoblastic bone metastases, an osteolytic reaction is also frequently present; however the mechanisms of stimulation of this osteolytic reaction have not been fully elucidated. It has been reported by us and others that CaP cells express RANKL mRNA and protein [14-16,29-33]. Moreover, we have shown that CaP cells in the bone environment express higher levels of RANKL than in primary tumors or soft-tissue metastases [14], and Zhang et al. demonstrated activation of transcription of RANKL in C4-2B cells in the tibiae of mice [34]. The critical role of RANKL/RANK signaling in CaP associated osteolysis has been demonstrated by studies showing that the inhibition of RANKL/RANK signaling decreases tumor associated osteolysis which subsequently results in decreased $\mathrm{CaP}$ growth in the bone environment $[16,18,20,35]$. We have shown previously that administration of OPG or over-expression of OPG inhibits the osteolytic response of the bone to C4-2 cells in vivo, clearly demonstrating a critical role for RANKL in this process $[18,21]$. Similar results were reported in breast cancer and myeloma bone metastases [23,36-38]. In our present study we set out to investigate whether RANKL expressed by human CaP cells in the murine bone environment is involved in direct stimulation of osteoclastogenesis and osteoclast activity or whether the increases in osteolysis are associated with the ability of the tumor cells to elaborate factors that induce host production of RANKL.

In patients RANKL is expressed by both osteoblasts and CaP cells, and it is impossible at present to distinguish the relative contributions of each cell type to the osteolytic component of bone metastases. In the C4-2 tibial injection model of experimental bone metastases, the tumor cells express human RANKL, while the osteoblasts express murine RANKL. The use of a xenograft model and a species-specific RANKL inhibitor provides an elegant model to discern the relative contributions of RANKL derived from tumor cells versus other cell types in the bone microenvironment. This is not possible when using molecules such as OPG-Fc, or soluble RANK-Fc, which each inhibit the action of both mouse and human RANKL. The use of a neutralizing muRANKL MAb might be an alterative way to test this hypothesis; however, we are not aware of an antibody that would specifically recognize murine RANKL and possess neutralizing capabilities.

In our experimental model of $\mathrm{CaP}$ growth in the bone, administration of the anti-huRANKL MAb did not significantly inhibit osteolysis associated with the growth of C42 cells in the bone, suggesting that the RANKL expressed by these tumor cells is not the driving force for tumorassociated osteolysis in this model. We hypothesize that the interactions between tumor cells and cells within the bone results in increased expression of RANKL on osteoblasts. In support of our hypothesis it has also been reported that DU 145 cells produce soluble factor(s), which increased local RANKL expression and activated both osteoclasts/osteoclast precursors [39]. Other groups 
Table I: Effect of huRANKL treatment of C4-2 cells on bone morphometry

\begin{tabular}{|c|c|c|c|c|c|c|c|}
\hline & BV/TV (\%) & TuV/TV (\%) & Tb.Th. $(\mu \mathrm{m})$ & Tb.N. $\left(\mathrm{mm}^{-1}\right)$ & Tb.Sp. $(\mu \mathrm{m})$ & Ob.Pm./B.Pm. (\%) & N.Oc./BS $(\# / \mathrm{mm})$ \\
\hline Control & $5.88 \pm 0.99$ & $80.48 \pm 2.49$ & $31.58 \pm 4.83$ & $2.03 \pm 0.42$ & $597.24 \pm 215.70$ & $5.23 \pm 1.03$ & $4.06 \pm 0.37$ \\
\hline Prevention & $6.65 \pm 2.31$ & $78.69 \pm 2.06$ & $34.27 \pm 2.05$ & $1.84 \pm 0.50$ & $690.77 \pm 188.80$ & $9.51 \pm 1.76^{a}$ & $4.37 \pm 0.71$ \\
\hline Treatment & $6.75 \pm 1.72$ & $77.85 \pm 2.99$ & $36.00 \pm 4.80$ & $1.79 \pm 0.37$ & $633.46 \pm 193.00$ & $8.35 \pm 2.66$ & $6.32 \pm 0.50^{b}$ \\
\hline
\end{tabular}

Bone histomorphometric analysis was performed in the area adjacent to the growth plate $(0.525-1.225 \mathrm{~mm}$ below the growth plate: site of injection, $\mathrm{n}=4$ in control and treatment animals; $n=5$ in prevention animals. Two animals were removed from the analysis due to sectioning difficulties. Results are expressed as mean \pm SE. Statistical significance was evaluated using student's paired $t$ test. a Control vs. prevention $(p<0.05)$. ${ }^{6}$ Control vs. treatment $(p<0.05)$. Abbreviations: \%BV/TV, percentage bone volume in tissue volume; \%TuV/TV, tumor volume in tissue volume as a percentage; Tb.Th., trabecular thickness in $\mu$ m; Tb.N., trabecular number per mm; Tb.Sp., trabecular seperation in $\mu \mathrm{m}$; Ob.Pm./B.Pm., osteoblast perimeter to bone perimeter; N.Oc./BS, ratio of osteoclast number to bone surface.

A

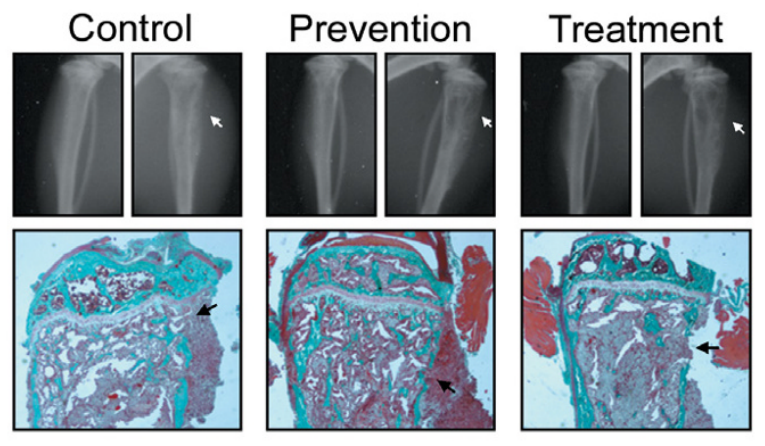

B

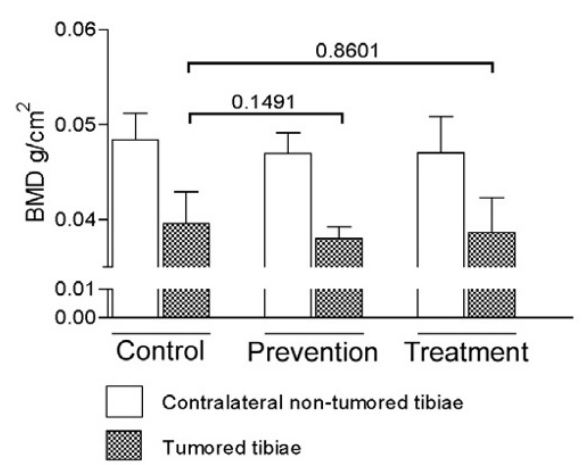

Figure 3

A: Characteristics of C4-2 tumor-bearing tibiae. Upper panel: radiographs of the right and left tibiae of representative animals from control, prevention, and treatment groups. Arrows indicate areas of the eroded cortical shaft in tumored tibiae of C4-2-treated animals. Middle panel: mineralized tibiae were harvested 8 weeks after tumor injection and embedded in methacrylate and $6 \mu \mathrm{m}$ sections were stained with Goldner's stain. In tumor-bearing animals the tumor replaced the marrow, filling the cavity and degrading the trabecular bone. Arrows indicate areas of the eroded cortical shaft where the tumor has started to extravasate. B: Bone mineral density (BMD) was measured 8 weeks after intra-tibial C4-2 injection in SCID mice. There was no significant difference in BMD between control and prevention $(p=0.1491)$ or control and treatment $(p=$ 0.8601 ) animals. Results are presented as mean \pm SE. have also determined that osteoblasts can upregulate osteoclastogenesis associated factors in response to breast and prostate cancer cells in vitro $[40,41]$. Furthermore, breast cancer cells altered the phenotype of osteoblast cells, causing increased expression of various osteoclast stimulating factors [42]. Potential candidate factors are IL-11 and osteopontin, which were shown to stimulate recruitment and activation of osteoclasts in breast cancer osteolytic metastases, and IL-7 that can stimulate spontaneous osteoclastogenesis in bone metastases [43,44]. Both of these proteins are also secreted by CaP cells $[45,46]$. IL- 11 is an interesting candidate gene, as IL-11 has been shown to increase RANKL expression in bone, and OPG fully prevented IL-11 induced bone resorption [47].

Another anti-human RANKL neutralizing antibody, AMG162 (denosumab, Amgen, Inc.), is a potent antiresorptive agent that is currently under clinical evaluation as a treatment for cancer-induced bone loss and other bone-loss disorders [48-50]. In patients, the tumor cells and osteoblasts express human RANKL and therefore denosumab will inhibit the actions of RANKL expressed by both cell types. In addition, the use of denosumab has potential advantages as a therapeutic agent over other RANKL inhibitors, such as OPG, because denosumab does not bind to TRAIL and it also has a longer half-life in vivo compared to OPG [51-53].

We detected significant decreases in serum levels of $\mathrm{Ca}^{2+}$ in the tumored animals associated with long-term administration of the anti-huRANKL MAb. This effect has not been observed in previous studies (our unpublished data). Since no other alteration consistent with effects on osteoclast number or activity was observed, we hypothesize that long-term administration of the anti-huRANKL $\mathrm{MAb}$ might exhibit weak effects on osteoclastogenesis caused by mouse RANKL or that administration of huRANKL MAb inhibits human RANKL/RANK signaling in the CaP cells, altering expression of other factors secreted by these cells that are involved in decreasing serum $\mathrm{Ca}^{2+}$ levels. 

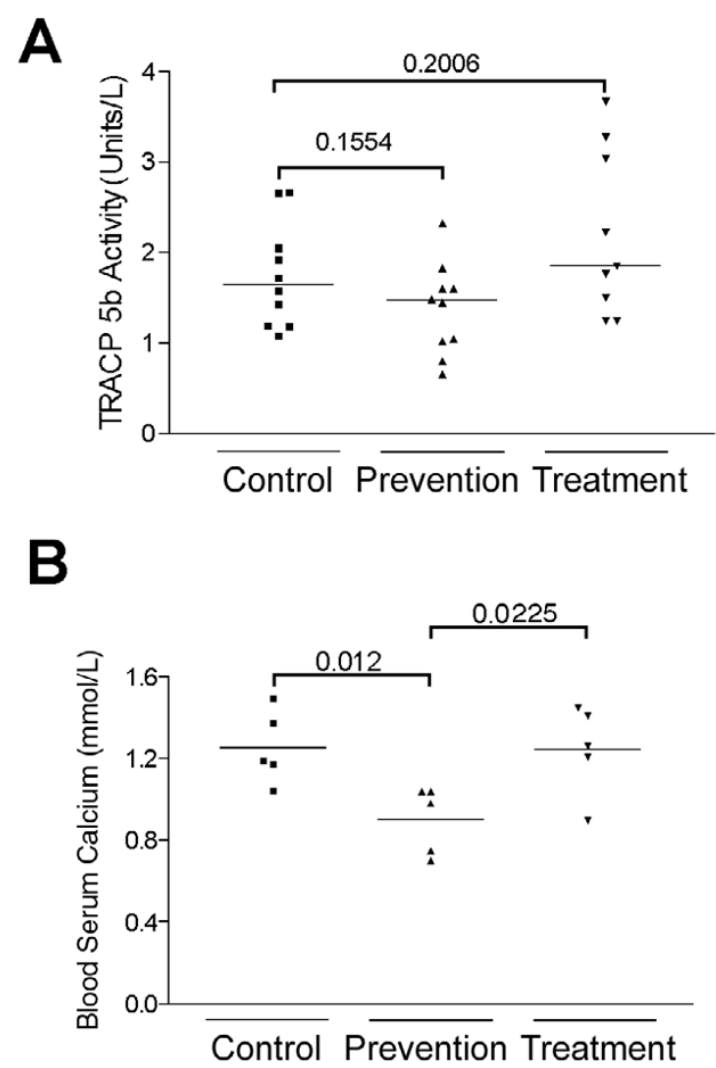

\section{Figure 4}

A: The tartrate-resistant acid phosphatase assay was performed according to the manufacturer's instructions on mouse serum samples from control, prevention, and treatment groups, using the Mouse TRAPTM Assay measuring TRACP-5b activity (Immunodiagnostic systems Inc.) $(n=10)$. There were no significant differences associated with huRANKL MAb administration. B: Serum calcium levels were measured using a calcium ion electrode 8 weeks after intratibial C4-2 injection in the control, prevention, and treatment groups. Serum calcium levels were significantly different between control and prevention animals $(p=0.012)$. Serum calcium levels were not significantly different between control and treatment animals $(p=0.9631)$.

As discussed above, we observed no increases in serum $\mathrm{Ca}^{2+}$ levels in animals treated with the anti-huRANKL MAb compared to untreated tumored animals. Nor did we observe increases in TRACP $5 b$ activity after antihuRANKL MAb administration. As the bone destruction and osteoclastic activity was localized to the right tibia and not systemic, our assays may not have been able to detect minor changes in TRACP 5b activity or serum $\mathrm{Ca}^{2+}$ levels. These assays do suggest, however, that the anti-
huRANKL antibody did not have a systemic effect on murine RANKL as osteoclast activity and serum $\mathrm{Ca}^{2+}$ levels did not alter between tumored animals and animals treated with anti-huRANKL MAb. This is a further indication that the antibody anti-huRANKL MAb does not interact with murine RANKL.

We are cognizant that these studies have certain limitations and are subject to alternative interpretations. For example, it could be argued that the dose of the antihuRANKL MAb $(5 \mathrm{mg} / \mathrm{kg}$ ) resulted in insufficient levels of the $\mathrm{MAb}$ in the tumor-bone microenvironment to inhibit huRANKL-mediated osteolysis. However, we do not believe that low levels of the huRANKL MAb are responsible for absence of an effect on osteoclast numbers, since a lower dose of huRANKL MAb (3 mg/kg) inhibited the action of high-dose human RANKL $(0.5 \mathrm{mg} / \mathrm{kg})$ in the circulation for four days. It is also possible that the inhibition kinetics of membrane bound and soluble RANKL are different. Prostate tumor cells were shown to produce membrane-bound as well as soluble RANKL [16], but the proportion of these forms in vivo has not been determined.

We attempted, but were unable, to demonstrate immunoreactivity of the huRANKL MAb on the C4-2 cells in the bone microenvironment of the tumor-bearing treated animals (data not shown). Not all antibodies recognize the targeted protein after formalin fixation and embedding in paraffin. Therefore the lack of immunoreactivity does not necessarily mean the absence of the target protein. In this particular case, because we have shown expression of RANKL in C4-2 cells in the tibiae using other antibodies, as well as RANKL expression in cells grown in vitro, we have concluded that the lack of immunoreactivity of RANKL under immunohistochemical conditions with the huRANKL MAb is due to its inability to recognize the protein in paraffin-embedded tissues. We believe that our selection of this model for our studies is justified for following reasons: 1) we have shown previously that their growth in the bone results in increases in bone destruction; 2) these cells express RANKL; and 3) RANKL is involved in this process.

In this study, administration of huRANKL MAb did not inhibit growth of C4-2 cells within the bone. Since administration of this antibody did not inhibit osteolysis, our results are consistent with the literature showing that inhibition of RANKL/RANK signaling by OPG does not inhibit the proliferation of tumor cells injected subcutaneously in mice [16]. Together these results support the hypothesis that the inhibition of tumor growth by OPG in the bone environment is due to the indirect effects of OPG, through the inhibition of osteolysis and the direct inhibition of RANK/RANKL signaling in tumor cells. 
However, RANKL signaling has been shown to be important for metastatic spread of tumor cells [54]. These effects were not amenable to study by the methods reported herein, since we injected tumor cells directly into the bone and therefore could not investigate release and trafficking of tumor cells or seeding of tumor cells at secondary sites.

\section{Conclusion}

In conclusion, while RANKL is expressed by CaP cells, and the anti-huRANKL MAb can effectively block activity of human RANKL, our data suggest that tumor-derived RANKL may not be a central player in promoting osteolysis in this model. Our current model supports the notion that C4-2 cells express a factor/s other than RANKL that are ultimately responsible for recruitment and activation of osteoclasts. Based on the ability of OPG to prevent osteolysis and reduce $\mathrm{CaP}$ tumor burden in bone, we hypothesize that CaP-derived factor(s) induce the production of RANKL within bone, which then culminates in local osteolysis and the stimulation of tumor growth. Our results warrant further studies to identify factors upstream of RANKL that may be involved in stimulating the osteolytic component observed in this model.

\section{Competing interests}

PJK is a regular full time employee of Amgen Inc., with ownership of stock and stock options. All other author(s) declare that they have no competing interests.

\section{Authors' contributions}

CM performed experiments, data analysis and drafted the manuscript. PJK performed experiments designed the study and modified the manuscript. LGB performed experiments and analysis of the data. RLV was involved in design of animal studies and discussion of the results. EC was involved in the design of the animal studies, discussion of the results, and modified the manuscript.

\section{Acknowledgements}

This research was supported by the National Institute of Health POI CA85859-0IA. CM was supported by a Career Development Award from the Pacific Northwest Prostate Cancer SPORE P50 CA097186. The authors would like to thank Austin Odman and Valerie Teske for excellent technical assistance and Dr. Michael Corey for editorial assistance. We would also like to thank Marina Stolina and Denise Dwyer for their work on the TRACP-5b animal study. The reagents for determination of PSA levels were kindly provided by Abbott Laboratories.

\section{References}

I. Roudier MP, True LD, Higano CS, Vesselle H, Ellis W, Lange P, Vessella RL: Phenotypic heterogeneity of end-stage prostate carcinoma metastatic to bone. Hum Pathol 2003, 34:646-653.

2. Shimazaki J, Higa T, Akimoto S, Masai M, Isaka S: Clinical course of bone metastasis from prostatic cancer following endocrine therapy: examination with bone x-ray. Adv Exp Med Biol 1992, 324:269-275.

3. Cheville JC, Tindall D, Boelter C, Jenkins R, Lohse CM, Pankratz VS, Sebo TJ, Davis B, Blute ML: Metastatic prostate carcinoma to bone: clinical and pathologic features associated with cancer-specific survival. Cancer 2002, 95: I028-1036.

4. Kuttig H: Radiotherapy of bone metastases. Rontgenblatter 1983 , 36:209-2I5.

5. Niell HB, Palmieri GM, Neely CL, Maxwell TA, Hopkins SC, Soloway MS: Total, Dialyzable, and Non-Dialyzable Postabsorptive Hydroxyproline - Values in Patients with Cancer. Arch Intern Med 1983, 143:1925-1927.

6. Koizumi M, Yamada Y, Takiguchi T, Nomura E, Furukawa M, Kitahara T, Yamashita T, Maeda H, Takahashi S, Aiba K, Ogata E: Bone Metabolic Markers in Bone Metastases. J Cancer Res Clin Oncol 1995, | 2 |:542-548.

7. Revilla M, Arribas I, Sanchez-Chapado M, Villa LF, Bethencourt F, Rico $\mathrm{H}$ : Total and regional bone mass and biochemical markers of bone remodeling in metastatic prostate cancer. Prostate 1998, 35:243-247.

8. Sugihara A, Maeda $O$, Tsuji M, Tsujimura T, Nakata $Y$, Akedo $H$, Kotake $T$, Terada $N$ : Expression of cytokines enhancing the osteoclast activity, and parathyroid hormone-related protein in prostatic cancers before and after endocrine therapy: An immunohistochemical study. Oncol Rep 1998, 5:1389-1394.

9. Berruti A, Dogliotti L, Bitossi R, Fasolis G, Gorzegno G, Bellina M, Torta M, Porpiglia F, Fontana D, Angeli A: Incidence of skeletal complications in patients with bone metastatic prostate cancer and hormone refractory disease: predictive role of bone resorption and formation markers evaluated at baseline. J Urol 2000, 164:1248-1253.

10. Blair JM, Zhou H, Seibel MJ, Dunstan CR: Mechanisms of disease: roles of OPG, RANKL and RANK in the pathophysiology of skeletal metastasis. Nat Clin Pract Oncol 2006, 3:4I-49.

II. Nakagawa N, Kinosaki M, Yamaguchi K, Shima N, Yasuda H, Yano K, Morinaga T, Higashio K: RANK is the essential signaling receptor for osteoclast differentiation factor in osteoclastogenesis. Biochem Biophys Res Commun 1998, 253:395-400.

12. Yasuda H, Shima N, Nakagawa N, Yamaguchi K, Kinosaki M, Mochizuki S, Tomoyasu A, Yano K, Goto M, Murakami A, Tsuda E, Morinaga T, Higashio K, Udagawa N, Takahashi N, Suda T: Osteoclast differentiation factor is a ligand for osteoprotegerin osteoclastogenesis-inhibitory factor and is identical to TRANCE/ RANKL. Proc Natl Acad Sci U S A 1998, 95:3597-3602.

13. Grimaud E, Soubigou L, Couillaud S, Coipeau P, Moreau A, Passuti N, Gouin F, Redini F, Heymann D: Receptor activator of nuclear factor kappaB ligand (RANKL)/osteoprotegerin (OPG) ratio is increased in severe osteolysis. Am J Pathol 2003, 163:202I-203I.

14. Brown JM, Corey E, Lee ZD, True LD, Yun T], Tondravi M, Vessella RL: Osteoprotegerin and rank ligand expression in prostate cancer. Urology 200I, 57:61 I-616.

15. Rubin J, Chung LWK, Fan X, Zhu L, Murphy TC, Nanes MS, Rosen CJ: Prostate carcinoma cells that have resided in bone have an upregulated IGF-I axis. Prostate 2004, 58:4I-49.

16. Zhang J, Dai JL, Qi YH, Lin DL, Smith P, Strayhorn C, Mizokami A, Fu Z, Westman J, Keller ET: Osteoprotegerin inhibits prostate cancer-induced osteoclastogenesis and prevents prostate tumor growth in the bone. J Clin Invest 200I, 107:1235-1244.

17. Lynch CC, Hikosaka A, Acuff HB, Martin MD, Kawai N, Singh RK, Vargo-Gogola TC, Begtrup JL, Peterson TE, Fingleton B, Shirai T, Matrisian LM, Futakuchi M: MMP-7 promotes prostate cancerinduced osteolysis via the solubilization of RANKL. Cancer Cell 2005, 7:485-496.

18. Quinn JE, Brown LG, Zhang J, Keller ET, Vessella RL, Corey E: Comparison of Fc-osteoprotegerin and zoledronic acid activities suggests that zoledronic acid inhibits prostate cancer in bone by indirect mechanisms. Prostate Cancer Prostatic Dis 2005, 8:253-259.

19. Zhang J, Dai JL, Yao Z, Lu Y, Dougall W, Keller ET: Soluble receptor activator of nuclear factor kappa B Fc diminishes prostate cancer progression in bone. Cancer Res 2003, 63:7883-7890.

20. Kiefer JA, Vessella RL, Quinn JE, Odman AM, Zhang J, Keller ET, Kostenuik P, Dunstan CR, Corey E: The effect of osteoprotegerin administration on the intra-tibial growth of the osteoblastic LuCaP 23.I prostate cancer xenograft. Clin Exp Metastasis 2004, 21:38I-387.

2I. Corey E, Brown LG, Kiefer JA, Quinn JE, Pitts TEM, Blair JM, Vessella $\mathrm{RL}$ : Osteoprotegerin in prostate cancer bone metastasis. Cancer Res 2005, 65: 1710-1718. 
22. Whang PG, Schwarz EM, Gamradt SC, Dougall WC, Lieberman JR: The effects of RANK blockade and osteoclast depletion in a model of pure osteoblastic prostate cancer metastasis in bone. J Orthop Res 2005, 23: | 475-| 483.

23. Morony S, Capparelli C, Sarosi I, Lacey DL, Dunstan CR, Kostenuik PJ: Osteoprotegerin inhibits osteolysis and decreases skeletal tumor burden in syngeneic and nude mouse models of experimental bone metastasis. Cancer Res 200I, 6 I:4432-4436.

24. Fisher JL, Thomas-Mudge RJ, Elliott J, Hards DK, Sims NA, Slavin J, Martin TJ, Gillespie MT: Osteoprotegerin overexpression by breast cancer cells enhances orthotopic and osseous tumor growth and contrasts with that delivered therapeutically. Cancer Res 2006, 66:3620-3628.

25. Croucher PI, Shipman CM, Van Camp B, Vanderkerken K: Bisphosphonates and osteoprotegerin as inhibitors of myeloma bone disease. Cancer 2003, 97:8I8-824.

26. Corey E, Quinn JE, Bladou F, Brown LG, Roudier MP, Brown JM, Buhler KR, Vessella RL: Establishment and characterization of osseous prostate cancer models: Intra tibial injection of human prostate cancer cells. Prostate 2002, 52:20-33.

27. Pfitzenmaier J, Quinn JE, Odman AM, Zhang JA, Keller ET, Vessella RL, Corey E: Characterization of C4-2 prostate cancer bone metastases and their response to castration. J Bone Miner Res 2003, I 8: $1882-1888$

28. Villanueva AR, Mehr LA: Modifications of Goldner and Gomori One-Step Trichrome Stains for Plastic-Embedded Thin-Sections of Bone. Am J Med Technol I 977, 43:536-538.

29. Brown JM, Vessella RL, Kostenuik PJ, Dunstan CR, Lange PH, Corey E: Serum osteoprotegerin levels are increased in patients with advanced prostate cancer. Clin Cancer Res 200I, 7:2977-2983

30. Lee Y, Schwarz E, Davies M, Jo M, Gates J, Wu J, Zhang X, Lieberman JR: Differences in the cytokine profiles associated with prostate cancer cell induced osteoblastic and osteolytic lesions in bone. J Orthop Res 2003, $21: 62-72$.

31. Asahi H, Mizokami A, Miwa S, Keller ET, Koshida K, Namiki M: Bisphosphonate induces apoptosis and inhibits pro-osteoclastic gene expression in prostate cancer cells. Int J Urol 2006, 13:593-600.

32. Perez-Martinez FC, Alonso V, Sarasa JL, Nam-Cha SG, Vela-Navarrete R, Manzarbeitia F, Calahorra FJ, Esbrit P: Immunohistochemical analysis of low-grade and high-grade prostate carcinoma: relative changes of parathyroid hormone-related protein and its parathyroid hormone I receptor, osteoprotegerin and receptor activator of nuclear factor-kB ligand. Clin Pathol 2007, 60:290-294.

33. Chen G, Sircar K, Aprikian A, Potti A, Goltzman D, Rabbani SA: Expression of RANKL/RANK/OPG in primary and metastatic human prostate cancer as markers of disease stage and functional regulation. Cancer 2006, 107:289-298.

34. Zhang J, Lu Y, Dai J, Yao Z, Kitazawa R, Kitazawa S, Zhao X, Hall DE, Pienta KJ, Keller ET: In vivo real-time imaging of TGF-betainduced transcriptional activation of the RANK ligand gene promoter in intraosseous prostate cancer. Prostate 2004, 59:360-369.

35. Wittrant $Y$, Theoleyre S, Chipoy C, Padrines M, Blanchard F, Heymann D, Redini F: RANKL/RANK/OPG: new therapeutic targets in bone tumours and associated osteolysis. Biochim Biophys Acta 2004, I 704:49-57.

36. Croucher PI, Shipman CM, Lippitt J, Perry M, Asosingh K, Hijzen A, Brabbs AC, van Beek EJ, Holen I, Skerry TM, Dunstan CR, Russell GR, Van Camp B, Vanderkerken K: Osteoprotegerin inhibits the development of osteolytic bone disease in multiple myeloma. Blood 200I, 98:3534-3540.

37. Zheng Y, Zhou H, Brennan K, Blair JM, Modzelewski JR, Seibel MJ, Dunstan CR: Inhibition of bone resorption, rather than direct cytotoxicity, mediates the anti-tumour actions of ibandronate and osteoprotegerin in a murine model of breast cancer bone metastasis. Bone 2007, 40:47|-478.

38. Doran PM, Turner RT, Chen D, Facteau SM, Ludvigson JM, Khosla S Riggs BL, Russell SJ: Native osteoprotegerin gene transfer inhibits the development of murine osteolytic bone disease induced by tumor xenografts. Exp Hematol 2004, 32:35I-359.

39. Mori K, Le GB, Charrier C, Battaglia S, Heymann D, Redini F: DUI 45 human prostate cancer cells express functional receptor activator of NFkappaB: new insights in the prostate cancer bone metastasis process. Bone 2007, 40:98I-990.

40. Inoue H, Nishimura K, Oka D, Nakai Y, Shiba M, Tokizane T, Arai $Y$, Nakayama M, Shimizu K, Takaha N, Nonomura N, Okuyama A: Prostate cancer mediates osteoclastogenesis through two different pathways. Cancer Lett 2005, 223:12I-I28.

4I. Thomas RJ, Guise TA, Yin J], Elliott J, Horwood NJ, Martin TJ, Gillespie MT: Breast cancer cells interact with osteoblasts to support osteoclast formation. Endocrinology 1999, 140:445I-4458.

42. Barnes GL, Hebert KE, Kamal M, Javed A, Einhorn TA, Lian JB, Stein GS, Gerstenfeld LC: Fidelity of Runx 2 activity in breast cancer cells is required for the generation of metastases-associated osteolytic disease. Cancer Res 2004, 64:4506-45।3.

43. Kang Y, Siegel PM, Shu W, Drobnjak M, Kakonen SM, Cordon-Cardo C, Guise TA, Massague J: A multigenic program mediating breast cancer metastasis to bone. Cancer Cell 2003, 3:537-549.

44. Roato I, Brunetti G, Gorassini E, Grano M, Colucci S, Bonello L, Buffoni L, Manfredi R, Ruffini E, Ottaviani D, Ciuffreda L, Mussa A, Ferracini R: IL-7 Up-Regulates TNF-alpha-Dependent Osteoclastogenesis in Patients Affected by Solid Tumor. PLOS ONE 2006, I:el 24.

45. Campbell CL, Jiang Z, Savarese DM, Savarese TM: Increased expression of the interleukin- II receptor and evidence of STAT3 activation in prostate carcinoma. Am J Pathol 200I, I 58:25-32.

46. Thalmann GN, Sikes RA, Devoll RE, Kiefer JA, Markwalder R, Klima I, Farach-Carson CM, Studer UE, Chung LW: Osteopontin: possible role in prostate cancer progression. Clin Cancer Res 1999, 5:227I-2277.

47. Ahlen J, Andersson S, Mukohyama H, Roth C, Backman A, Conaway $\mathrm{HH}$, Lerner $\mathrm{UH}$ : Characterization of the bone-resorptive effect of interleukin- II in cultured mouse calvarial bones. Bone 2002, 3I:242-25I.

48. Dougall W, Chaisson M: [A Monoclonal Antibody Targeting RANKL as a Therapy for Cancer-induced Bone Diseases.]. Clin Calcium 2006, 16:627-635.

49. McClung MR, Lewiecki EM, Cohen SB, Bolognese MA, Woodson GC, Moffett AH, Peacock M, Miller PD, Lederman SN, Chesnut CH, Lain D, Kivitz AJ, Holloway DL, Zhang C, Peterson MC, Bekker PJ: Denosumab in postmenopausal women with low bone mineral density. N Engl J Med 2006, 354:82I-83I.

50. Body JJ, Facon T, Coleman RE, Lipton A, Geurs F, Fan M, Holloway D, Peterson MC, Bekker PJ: A study of the biological receptor activator of nuclear factor-kappaB ligand inhibitor, denosumab, in patients with multiple myeloma or bone metastases from breast cancer. Clin Cancer Res 2006, I 2:1221-1228.

5I. Bekker PJ, Holloway DL, Rasmussen AS, Murphy R, Martin SW, Leese PT, Holmes GB, Dunstan CR, DePaoli AM: A single-dose placebocontrolled study of AMG 162 , a fully human monoclonal antibody to RANKL, in postmenopausal women. J Bone Miner Res 2005, 20:2274-2282.

52. Abrahamsen B, Teng AYT: Technology evaluation: Denosumab, Amgen. Curr Opin Mol Ther 2005, 7:604-6IO.

53. Kostenuik PJ: Osteoprotegerin and RANKL regulate bone resorption, density, geometry and strength. Curr Opin Pharmacol 2005, 5:6 18-625.

54. Jones DH, Nakashima T, Sanchez OH, Kozieradzki I, Komarova SV, Sarosi I, Morony S, Rubin E, Sarao R, Hojilla CV, Komnenovic V, Kong YY, Schreiber M, Dixon SJ, Sims SM, Khokha R, Wada T, Penninger JM: Regulation of cancer cell migration and bone metastasis by RANKL. Nature 2006, 440:692-696.

\section{Pre-publication history}

The pre-publication history for this paper can be accessed here:

http://www.biomedcentral.com/1471-2407/7/148/pre pub 